\title{
Effects of Cooling Rate on Growth Behavior of Austenite Phase during Peritectic Reaction in Iron-Carbon Binary Alloy
}

\author{
Kiyotaka MATSUURA, Hisashi MARUYAMA,"1) Masayuki KUDOH and Youichi ITOH
}

Division of Materials Science and Engineering, Graduate School of Engineering, Hokkaido University, Kita-ku, Sapporo, Hokkaido, 060 Japan. E-mail: mat@e2.hines.hokudai.ac.jp 1) Graduate Student, Graduate School of Engineering, Hokkaido University.

(Received on April 19, 1995; accepted in final form on June 19, 1995)

\begin{abstract}
A model experiment of peritectic reaction during cooling of an iron-carbon binary alloy is performed by using a solid-liquid diffusion couple method, and the effects of cooling rate on the growth behavior of austenite phase is investigated. A numerical simulation of the growth process of austenite phase during the peritectic reaction also is performed by using the method previously proposed by the present authors. Both the experimental and simulated results show that austenite phase formed at $\delta$-ferrite/liquid interface grows into both $\delta$-ferrite phase and liquid phase during cooling and that its growth rate increases with increasing cooling rate.
\end{abstract}

KEY WORDS: peritectic reaction; reaction rate; simulation; solidification; transformation; diffusion; iron-carbon system.

\section{Introduction}

In casting process of steels containing carbon ranging from 0.1 to 0.5 mass $\%$, austenite is produced as secondary crystal by peritectic reaction between primary crystal of $\delta$-ferrite and residual liquid. ${ }^{1)}$ Because the physical properties of austenite are significantly different from those of $\delta$-ferrite, peritectic reaction leads to some undesirable phenomena such as generation of tensile stress, ${ }^{2)}$ segregation of alloying elements, ${ }^{3)}$ precipitation of inclusions, ${ }^{4)}$ and so on. An important guide for optimum control of these phenomena is considered to be the rate of peritectic reaction.

The present authors ${ }^{5,6)}$ have measured the rate of isothermal peritectic reaction in iron-carbon binary system by using a solid-liquid diffusion couple method, and have found that isothermal peritectic reaction proceeds in accordance with the parabolic law and that the parabolic rate constant increases with decreasing temperature. Additionally, the present authors ${ }^{7)}$ have numerically simulated the growth behavior of austenite phase during peritectic reaction in the cooling process of an iron-carbon binary alloy, and have found that the growth rate of austenite phase increases with increasing cooling rate.

The present study intends to make experimental verification of the preceding simulation results.

\section{Procedure}

A model experiment of peritectic reaction in the cooling process of carbon steel was carried out by using a solid-liquid diffusion couple method. ${ }^{5,6)}$ The diffusion couple was formed at $1755 \mathrm{~K}$, and was then cooled at a given cooling rate. At $1755 \mathrm{~K}$, according to an ironcarbon binary equilibrium phase diagram, ${ }^{1)}$ peritectic reaction takes place between $\delta$-ferrite phase of 0.08 mass $\%$ carbon and liquid phase of 0.74 mass $\%$ carbon, and produces austenite phase of carbon concentration ranging from 0.15 mass $\%$ at $\delta$-ferrite/austenite interface to 0.23 mass $\%$ at austenite/liquid interface. It was supposed that in the cooling process from $1755 \mathrm{~K}$, austenite phase grows both into $\delta$-ferrite phase and into liquid phase, accompanying the change in the values of equilibrium carbon concentration at each interface.

Because the fundamentals of the present experimental procedure are similar to those detailed in a previous paper, ${ }^{5)}$ only the outline of the procedure is described below.

Liquid phase as one of the reactants of the peritectic reaction was prepared in the following way. A high carbon alloy (carbon content: 0.7 mass $\%$, mass: $30 \mathrm{~g}$ ) was melted at $1803 \mathrm{~K}$ in a high purity alumina crucible (inner diameter and depth: 35 and $50 \mathrm{~mm}$ ) in an argon atmosphere in a vertical type $\mathrm{SiC}$ furnace, and was cooled to $1755 \mathrm{~K}$ at a cooling rate of $1.39 \times 10^{-2} \mathrm{~K} / \mathrm{s}$. At $1755 \mathrm{~K}$, according to the phase diagram, this high carbon alloy is partially solidified, and liquid phase of 0.74 mass $\%$ carbon coexists with a very small amount of austenite phase of 0.23 mass $\%$ carbon. The liquid phase being conjugated with the austenite phase on the bottom of the crucible was selectively used as the initial liquid phase which takes part in the peritectic reaction with $\delta$-ferrite phase.

While liquid phase was prepared in the above-described way, $\delta$-ferrite phase as the other reactant of the 
peritectic reaction was simultaneously prepared in the same furnace. A cylinder-shaped low carbon alloy (carbon content: 0.08 mass $\%$, diameter and thickness: 25 and $15 \mathrm{~mm}$ ) was suspended by an alumina tube (outer and inner diameters: 6 and $4 \mathrm{~mm}$ ) from the top of the furnace, and was held in a low temperature part in the furnace. After the above-described high carbon molten alloy was cooled to $1755 \mathrm{~K}$, this low carbon alloy was moved down to a position just above the surface of the liquid phase in the crucible. This low carbon alloy was used as the initial $\delta$-ferrite phase which takes part in the peritectic reaction with the liquid phase. After holding for $3.6 \mathrm{ks}$ in this alignment, the $\delta$-ferrite phase and liquid phase were slowly brought into contact to form a solidliquid diffusion couple, and were then cooled at a given cooling rate ranging from $0.14 \times 10^{-3}$ to $5.56 \times 10^{-3} \mathrm{~K} / \mathrm{s}$. After a predetermined time passed, the diffusion couple was rapidly quenched by dropping into vigorously stirred iced water together with the crucible.

The quenched sample was etched with nital etchant on the longitudinal section, and the thickness of austenite phase formed at the interface between $\delta$-ferrite phase and liquid phase was measured. Furthermore, the variations of carbon concentration were measured over $\delta$-ferrite phase, austenite phase and liquid phase by the EPMA method (JXA-8900M, JEOL). The purity of the sample was $\mathrm{Si}<0.01, \mathrm{Mn}<0.01, \quad \mathrm{P}<0.002, \mathrm{~S}<0.002$, and Sol.Al $<0.01$ mass $\%$.

\section{Results}

Figure 1 shows the microstructure of a sample cooled from 1755 to $1738 \mathrm{~K}$ at a rate of $5.56 \times 10^{-3} \mathrm{~K} / \mathrm{s}$. Large crystal grains of austenite phase were formed at $\delta$-ferrite/liquid interface. The location of initial $\delta$ ferrite/liquid interface (shown by an arrow in the figure) is determined from the initial thickness of the cylindershaped low carbon alloy. At the initial $\delta$-ferrite/liquid interface, no grain boundary of austenite phase is observed, which suggests that the austenite grain which nucleates at the initial $\delta$-ferrite/liquid interface grows both into $\delta$-ferrite phase by transformation and into liquid phase by solidification. From the location of the initial $\delta$-ferrite/liquid interface, the thickness of transformed austenite and that of solidified one are able to be separately measured.

Figure 2 shows the distribution of carbon concentration over $\delta$-ferrite, austenite and liquid phases in the same sample as is shown in Fig. 1. Symbols $C_{1}$ to $C_{4}$ in Fig. 2 indicate the equilibrium carbon concentrations at the interfaces at the quenching temperature, as shown in Fig. 3. According to the results shown in Fig. 2, in austenite phase, carbon concentration decreases from $C_{3}$ at austenite/liquid interface to $C_{2}$ at $\delta$-ferrite/austenite interface, while both in liquid and $\delta$-ferrite phases, carbon concentration shows violent variations within the ranges between $C_{3}$ and $C_{4}$ and between $C_{1}$ to $C_{2}$, respectively. The decrease in carbon concentration from $C_{3}$ to $C_{2}$ in austenite phase was also observed in isothermal peritectic reaction previously studied by the present authors, ${ }^{5,6)}$ and it indicates that peritectic

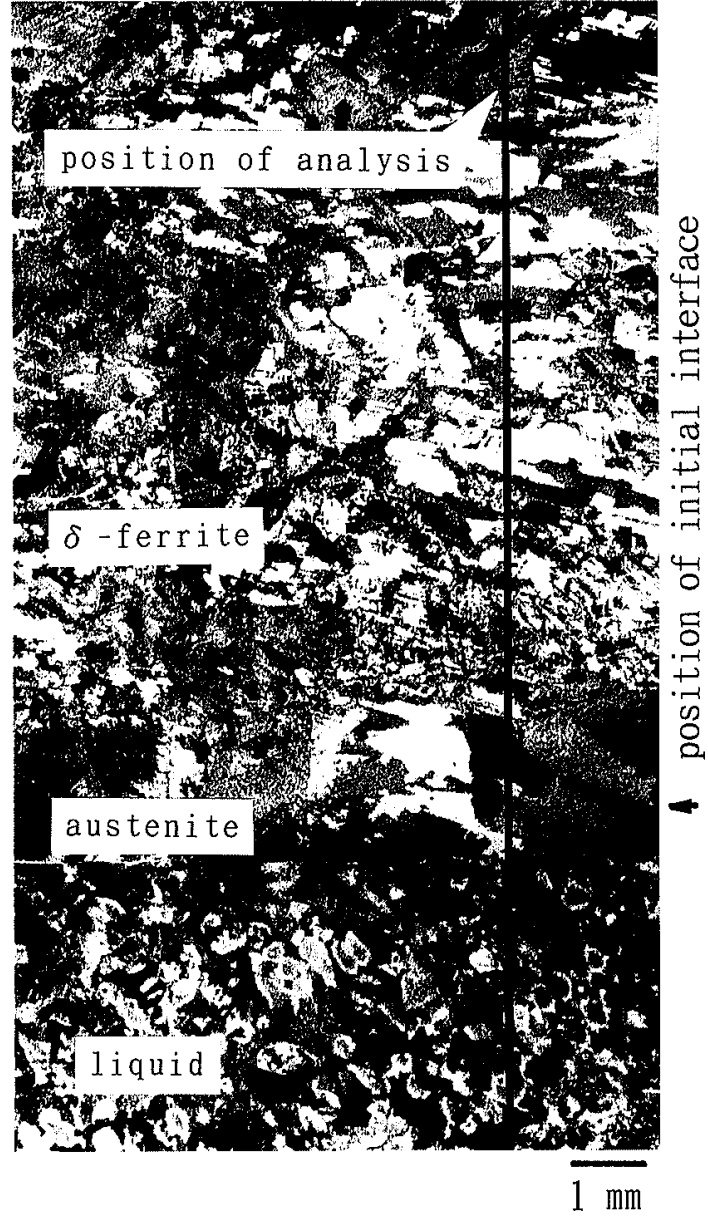

Fig. 1. Microstructure of a sample quenched from $1738 \mathrm{~K}$ after cooling from $1755 \mathrm{~K}$ at a rate of $5.56 \times 10^{-3} \mathrm{~K} / \mathrm{s}$ showing growth of austenite formed at $\delta$-ferrite/liquid interface.

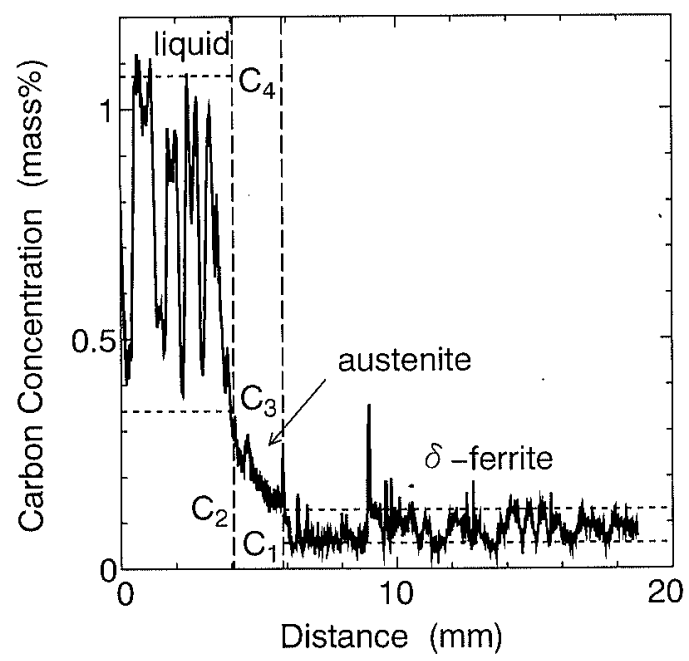

Fig. 2. Variation of carbon concentration along the straight line seen in Fig. 1.

reaction proceeds by carbon diffusion from liquid phase through austenite phase into $\delta$-ferrite phase, as known as the diffusion-controlled mechanism. ${ }^{8,9)}$ On the other hand, the significant variations in carbon concentration in liquid and $\delta$-ferrite phases were not observed in the isothermal peritectic reaction; this indicates that austenite phase crystallized in liquid phase and precipitated 


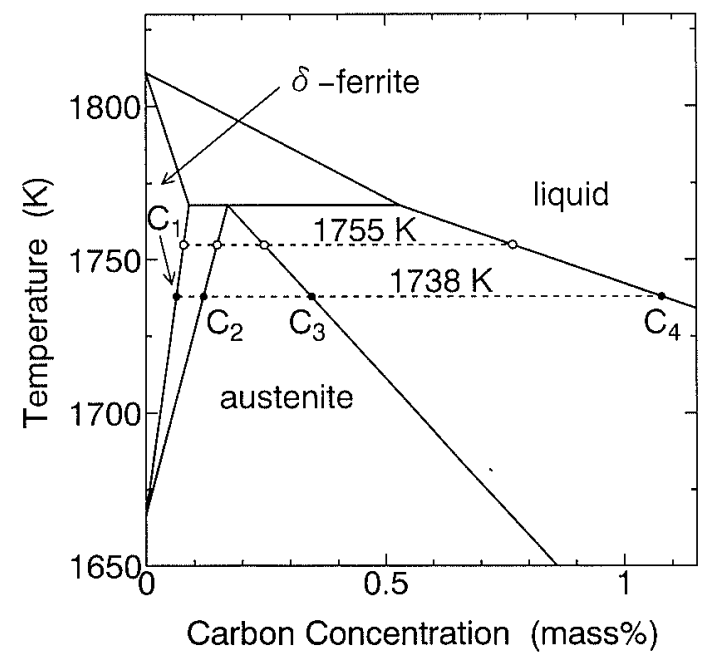

Fig. 3. Schematic iron-carbon binary equilibrium phase diagram. ${ }^{11}$

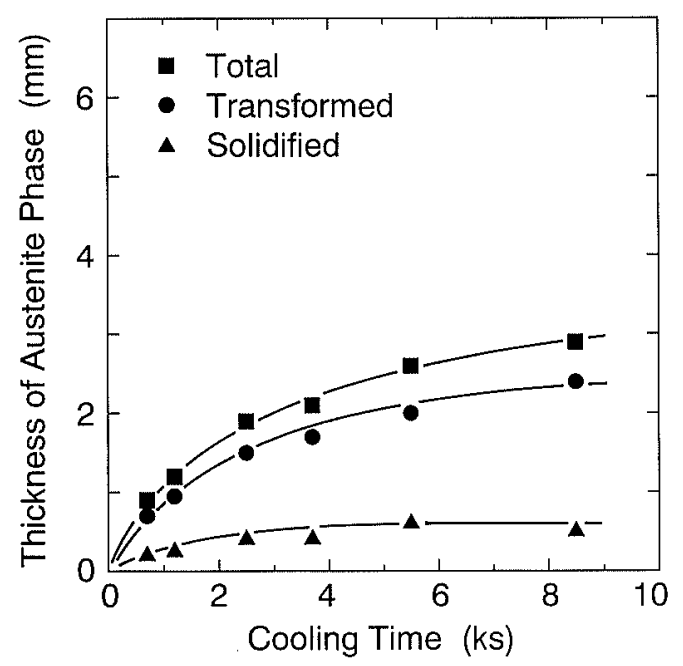

Fig. 4. Relationship between the thickness of austenite phase and cooling time. Cooling rate: $0.14 \times 10^{-3} \mathrm{~K} / \mathrm{s}$.

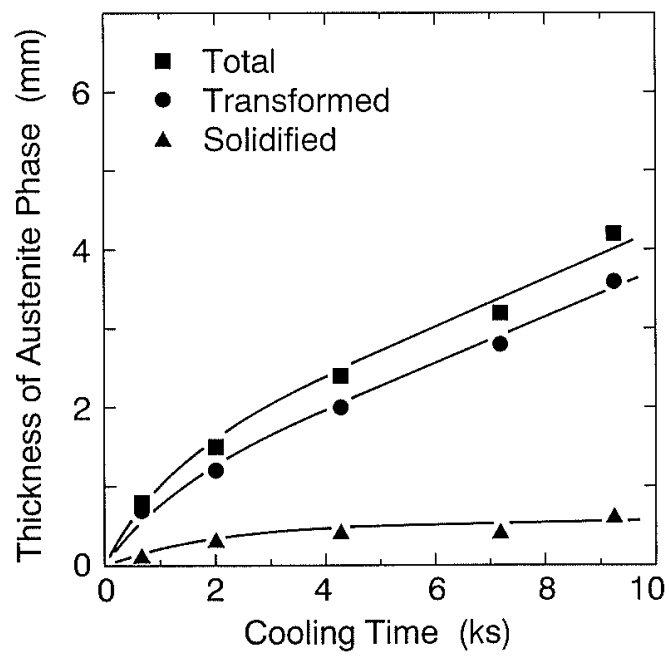

Fig. 5. Relationship between the thickness of austenite phase and cooling time. Cooling rate: $1.38 \times 10^{-3} \mathrm{~K} / \mathrm{s}$.

in $\delta$-ferrite phase during cooling of the diffusion couple.

Figures 4 through 7 show the relationships between the thickness of austenite phase and cooling time at various cooling rates. The growth of austenite phase by

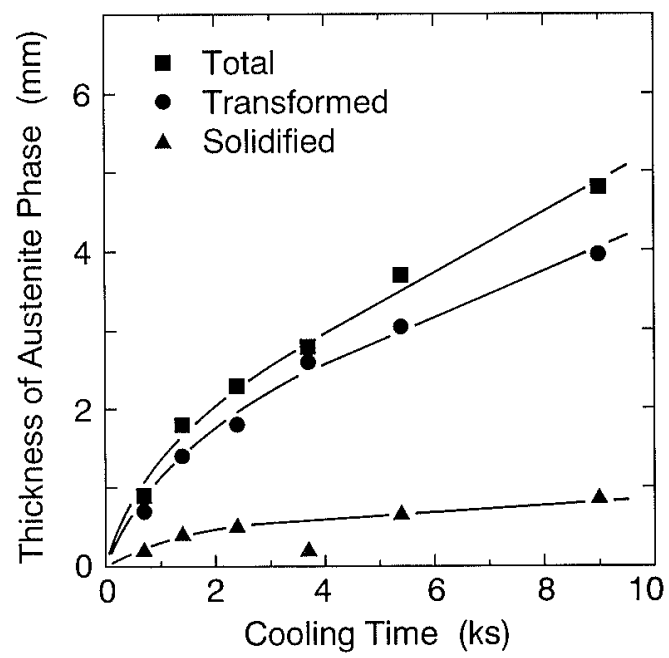

Fig. 6. Relationship between the thickness of austenite phase and cooling time. Cooling rate: $2.78 \times 10^{-3} \mathrm{~K} / \mathrm{s}$.

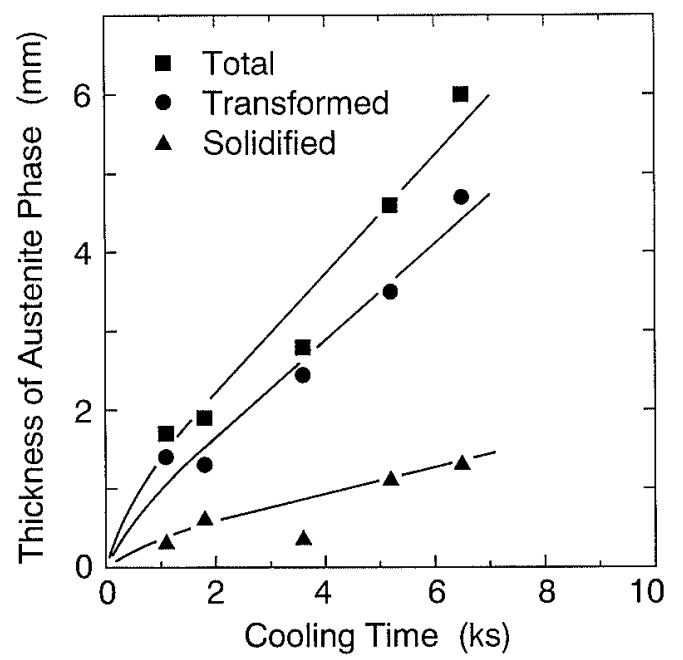

Fig. 7. Relationship between the thickness of austenite phase and cooling time. Cooling rate: $5.56 \times 10^{-3} \mathrm{~K} / \mathrm{s}$.

transformation is faster than that by solidification at all cooling rates. This is understood from the smaller difference in carbon concentration at $\delta$-ferrite/austenite interface than at austenite/liquid interface. ${ }^{6}$ ) As cooling rate increases, the thickness of austenite phase increases rapidly with increasing cooling time.

Figure 8 shows the effects of cooling rate on the relationship between the total thickness of austenite phase and square root of cooling time. When the diffusion couple is held at $1755 \mathrm{~K},{ }^{6}$ ) the thickness of austenite phase increases linearly, which means that the isothermal growth of austenite phase follows the parabolic law. When the diffusion couple is cooled from $1755 \mathrm{~K}$, however, the growth behavior of austenite phase deviates from the parabolic law, and the deviation becomes more appreciable as cooling rate increases.

\section{Discussion}

\subsection{Comparison with Previously Reported Results}

We have recently performed a numerical simulation of the growth behavior of austenite phase during peritectic reaction in the cooling process of an iron-carbon binary alloy, by combining the diffusion-controlled 


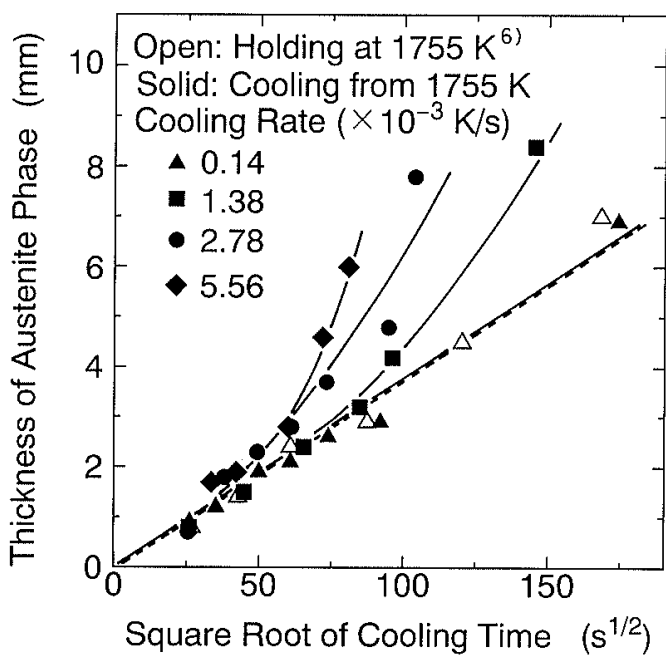

Fig. 8. Effects of cooling rate on the relationship between the total thickness of austenite phase and square root of cooling time.

mechanism with precipitation and crystallization mechanism. ${ }^{7)}$ The results are summarized in Fig. 9. Chuang et $a .^{8)}$ calculated the peritectic reaction process during solidification of an $1 \mathrm{t}$ slab of an iron-carbon alloy containing 0.39 mass $\%$ carbon, by using the diffusioncontrolled mechanism. Their results are replotted in Fig. 10. It is shown in Figs. 9 and 10 that the growth of austenite phase becomes rapid as cooling rate increases, and it qualitatively agrees with the results in the present model experiment shown in Figs. 4 through 8.

However, in the strict sense, quantitative comparison is not possible between the results of the calculation and the present experiment, because the conditions of the peritectic reaction are significantly different between the previous calculations and the present experiment. In the simulation previously performed by us, the volume element of $100 \mu \mathrm{m}$ in length including $\delta$-ferrite, austenite and liquid phases was cooled from $1767 \mathrm{~K}$ at a cooling rate ranging from 0.01 to $10 \mathrm{~K} / \mathrm{s}$. In the calculation by Chuang et al., the length of the volume element ranged from 141 to $60 \mu \mathrm{m}$ depending upon the cooling rate ranging from 0.113 to $1.563 \mathrm{~K} / \mathrm{s}$, and the starting temperature of peritectic reaction was $1767 \mathrm{~K}$. On the other hand, in the present model experiment, the volume element of approximately $20000 \mu \mathrm{m}$ in length is cooled from $1755 \mathrm{~K}$ at a cooling rate ranging from $0.14 \times 10^{-3}$ to $5.56 \times 10^{-3} \mathrm{~K} / \mathrm{s}$. Therefore, we need to simulate the change in the thickness of austenite phase during cooling by the method we have proposed in a previous paper ${ }^{\text {7) }}$ and by applying the same conditions used in the present experiment.

\subsection{Simulation}

The outline of the simulation method detailed in our previous paper ${ }^{7)}$ is briefly described below.

Continuous cooling process was simulated as repeating of the sequence of isothermal holding and quenching in a very small step both in time, $\Delta t$, and temperature, $\Delta T$. We assumed that (1) austenite phase grows by the diffusion of carbon during isothermal holding and by the precipitation from $\delta$-ferrite phase and crystallization from liquid phase on quenching, (2) carbon diffuses in

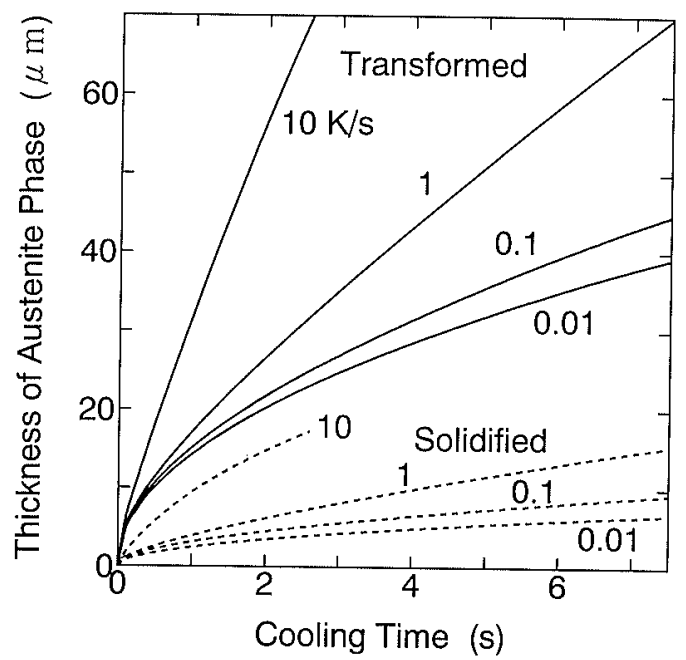

Fig. 9. Effects of cooling rate on the growth behavior of austenite. After Matsuura et al. ${ }^{7}$ )

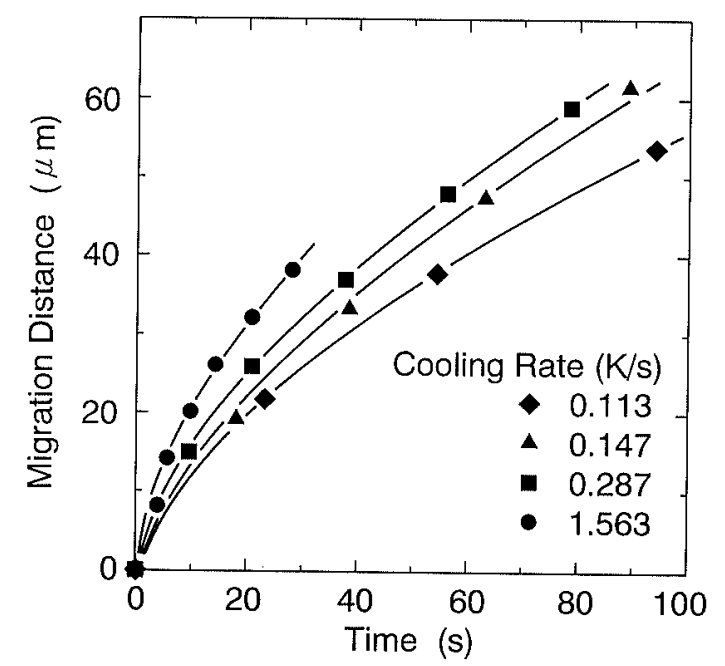

Fig. 10. Effects of cooling rate on the migration distance of austenite/liquid interface. After Chuang et al. $^{8 \text { ) }}$

$\delta$-ferrite and liquid phases completely, and (3) austenite phase nucleates from $\delta$-ferrite phase at $\delta$-ferrite/austenite interface and from liquid phase at austenite/liquid interface on quenching.

\subsubsection{Growth by Diffusion}

Because the diffusional growth of austenite phase proceeds in accordance with the parabolic law, ${ }^{5-9)}$ the relationship between the thickness of austenite phase, $x$, and time, $t$, is given by Eq. (1).

$$
x=a t^{1 / 2}
$$

The parabolic rate constant, $a$, is given in Eqs. (2) and (3) for the migration of $\delta$-ferrite/austenite interface and that of austenite/liquid interface, respectively. ${ }^{7)}$

$$
\begin{aligned}
& a_{\delta / \gamma}=4.27(D C)^{1 / 2} \\
& a_{\gamma / L}=0.86(D C)^{1 / 2}
\end{aligned}
$$

where $D$ is the diffusion coefficient of carbon in austenite phase and $C$ is the range of carbon concentration in austenite phase, $C_{3}-C_{2}$. Both $D$ and $C$ are expressed as functions of temperature in Eqs. (4) ${ }^{10)}$ and $(5),{ }^{1)}$ respectively. 


$$
\begin{aligned}
& D=0.761 \times 10^{8} \exp \left(-32160 R^{-1} T^{-1}\right) \quad\left(\mu \mathrm{m}^{2} \mathrm{~s}^{-1}\right) \\
& C=-7.545 \times 10^{-3} T+13.34 \quad(\text { mass } \%)
\end{aligned}
$$

where $R$ is the gas constant $\left(\mathrm{cal} \mathrm{K}^{-1} \mathrm{~mol}^{-1}\right)$ and $T$ the absolute temperature $(\mathrm{K})$.

The increment in thickness of austenite phase by the diffusional growth during isothermal holding for $\Delta t$ is given in Eq. (6).

$$
\Delta x_{\mathrm{Dif}}=(\mathrm{d} x / \mathrm{d} t) \Delta t
$$

Because $(\mathrm{d} x / \mathrm{d} t)$ in Eq. (6) is the velocity of interface migration and is obtained by differentiating Eq. (1), one can obtain the increments in thickness of austenite phase by the migration of $\delta$-ferrite/austenite interface and austenite/liquid interface from Eqs. (7) and (8), respectively.

$$
\begin{aligned}
& \Delta x_{\mathrm{Dif}, \delta / \gamma}=a_{\delta / \gamma}^{2}(2 x)^{-1} \Delta t \\
& \Delta x_{\mathrm{Dif}, \gamma / L}=a_{y / L}^{2}(2 x)^{-1} \Delta t
\end{aligned}
$$

\subsubsection{Growth by Precipitation and Crystallization}

The carbon concentrations in equilibrium at the interfaces between phases shown in Fig. 3 are expressed as functions of temperature in Eqs. (9) through (12).

$$
\begin{aligned}
& C_{1}=8.91 \times 10^{-4} T-1.48 \ldots \\
& C_{2}=1.68 \times 10^{-3} T-2.81 \ldots \\
& C_{3}=-5.86 \times 10^{-3} T+10.53 \\
& C_{4}=-1.83 \times 10^{-2} T+32.89
\end{aligned}
$$

As a result of quenching from $T$ to $(T-\Delta T)$, the carbon concentration in $\delta$-ferrite phase and austenite phase at the interface decrease from $C_{1}$ and $C_{2}$ to $C_{1}^{\prime}$ and $C_{2}^{\prime}$, respectively. The carbon concentration in $\delta$-ferrite phase becomes excessive by $\left(C_{1}-C_{1}^{\prime}\right)$ owing to the decrease in the equilibrium carbon concentration of $\delta$-ferrite phase from $C_{1}$ to $C_{1}^{\prime}$. This amount of carbon is assumed to be consumed by the precipitation of austenite phase at $\delta$-ferrite/austenite interface. Therefore, the thickness of austenite phase precipitated on quenching by $\Delta T$ is expressed as Eq. (13).

$$
\Delta x_{\delta / \gamma}=x_{\delta}\left(C_{1}-C_{1}^{\prime}\right) /\left(C_{2}^{\prime}-C_{1}^{\prime}\right)
$$

where $x_{\delta}$ is the thickness of $\delta$-ferrite phase at the temperature just before quenching by $\Delta T$. Similarly, the thickness of austenite phase crystallized at austenite/ liquid interface on quenching by $\Delta T$ is expressed as Eq. (14).

$$
\Delta x_{y / L}=x_{L}\left(C_{4}^{\prime}-C_{4}\right) /\left(C_{4}^{\prime}-C_{3}^{\prime}\right)
$$

where $x_{L}$ is the thickness of liquid phase at the temperature just before the quenching.

\subsection{Comparison between Experimental and Simulated Results}

Figure 11 shows the results of the simulation performed by using the conditions in the present model experiment. The results of the simulation are qualitatively very similar to those of the present experiment shown in Fig. 8. However, the values of the thickness of austenite phase

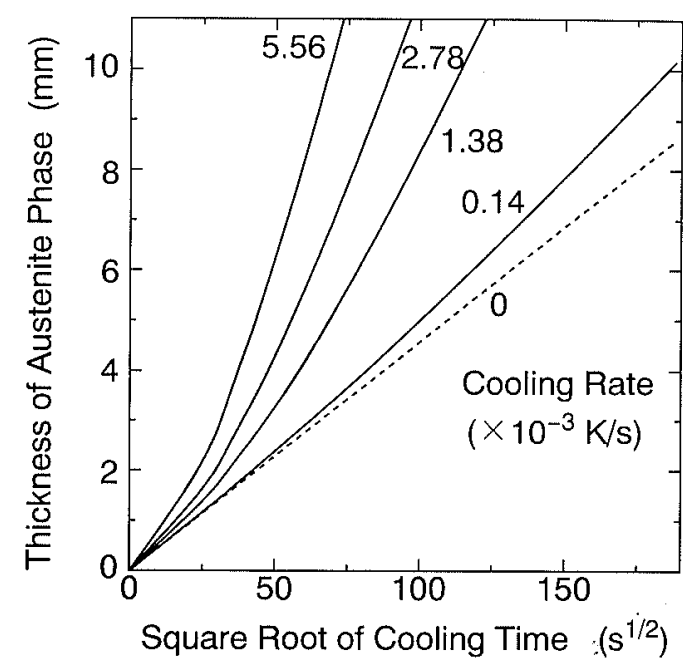

Fig. 11. Effects of cooling rate on the growth behavior of austenite. Calculated to compare with the experimental results in Fig. 8.

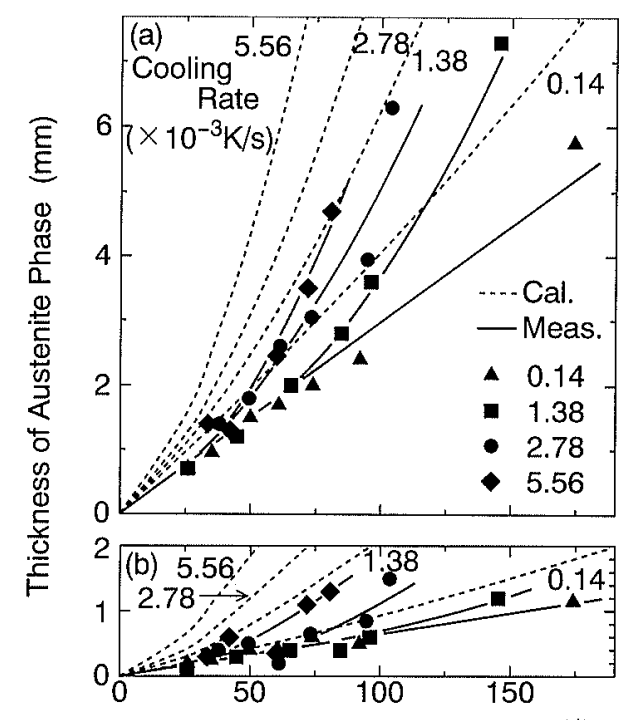

Square Root of Cooling Time $\left(s^{1 / 2}\right)$

Fig. 12. Comparison between the measured and calculated results for the austenite growth by transformation (a) and by solidification (b).

in Fig. 8 are a little smaller than those in Fig. 11. The reason for the difference is considered to be as follows.

In the simulation, it was assumed that on the temperature drop by $\Delta T$, excessive carbon in $\delta$-ferrite phase is consumed by the precipitation of austenite phase at $\delta$-ferrite/austenite interface and deficient carbon in liquid phase is supplemented by the crystallization of austenite phase at austenite/liquid interface. In the experiment, on the contrary, both the precipitation and crystallization of austenite phase take place apart from the interfaces, as shown in Fig. 2. The formation of austenite phase apart from the interfaces results in smaller thicknesses of austenite phase in the experimental results than in the simulated results.

The comparison between the measured and calculated results shown in Fig. 12 supports the consideration described above. It is supposed that because the nucleation of austenite phase apart from the interfaces becomes difficult owing to a small undercooling of $\delta$-ferrite and 
liquid phases when the cooling rate is low, the measured and calculated results become closer as the cooling rate decreases, as shown in Fig. 12. The difference between the measured and calculated results, however, is not considered to lower the value of our preceding simulation. ${ }^{7)}$ Precipitation or crystallization may not take place apart from the interfaces in practical steel casting, because the dendrite arm spacings including $\delta$-ferrite, austenite and liquid phases in practical steel casting are significantly smaller than the size of the diffusion couple used in the present model experiment, and therefore austenite phase surely forms at the interfaces as assumed in the simulation.

The formation of austenite phase in the dendritic structure of $\delta$-ferrite phase leads to the generation of stress in the solidification shell because of the difference in the density between those phases. When the growth rate of austenite phase is low, the stress may be relaxed without generating cracks. It is, therefore, suggested that slow cooling is preferable to crack avoidance, since the present results show that the peritectic reaction proceeds faster as cooling rate increases.

\section{Conclusions}

A model experiment of peritectic reaction in an iron-carbon binary alloy was performed by using a solid-liquid diffusion couple method, and the effects of cooling rate on the growth behavior of austenite phase was investigated. Additionally, the growth process of austenite phase in the diffusion couple was numerically simulated by using the method previously proposed by the present authors to verify experimentally the calculation method by comparing both the results. The following conclusions were obtained.

(1) Austenite phase is formed at $\delta$-ferrite/liquid interface, and it grows into both $\delta$-ferrite phase and liquid phase during cooling. As cooling rate increases, the growth behavior of austenite phase deviates from the parabolic law and the growth rate increases.

(2) The experimental results are consistent with the numerically simulated results, although the thickness of austenite phase is a little overestimated in the simulation. Therefore, the calculation procedure for the numerical simulation of the peritectic reaction was experimentally verified.

\section{Acknowledgement}

The authors gratefully acknowledge the financial support of the Iron-and-Steel Research Promotion Fund for 1994 fiscal year from The Iron and Steel Institute of Japan in performing this study.

\section{REFERENCES}

1) T. B. Massalski: Binary Alloy Phase Diagrams, Vol. 1, ASM, Materials Park, (1990), 842.

2) T. Matsumiya, T. Saeki, J. Tanaka and T. Ariyoshi: Tetsu-toHagané, 68 (1982), 1782.

3) H. Fredriksson: Scand. J. Metall., 5 (1976), 27.

4) Y. Itoh, N. Narita and K. Matsubara: Tetsu-to-Hagané, 67 (1981), 755.

5) K. Matsuura, Y. Itoh and T. Narita: ISIJ Int., 33 (1993), 583.

6) K. Matsuura, H. Maruyama, Y. Itoh, M. Kudoh and K. Ishii: ISIJ Int., 35 (1995), 183.

7) K. Matsuura, M. Kudoh and T. Ohmi: ISIJ Int., 35 (1995), 624.

8) Y. K. Chuang, D. Reinisch and K. Schwerdtfeger: Metall. Trans. A, 6A (1975), 235.

9) H. Fredriksson and S. Stjerndahl: Met. Sci., 16 (1982), 575.

10) Y. Ueshima, S. Mizoguchi, T. Matsumiya and H. Kajioka: Metall. Trans. B, 17B (1986), 845. 